\title{
Perceived community environment and physical activity involvement in a northern-rural Aboriginal community Allison M Kirby* ${ }^{* 1,3}$, Lucie Lévesque ${ }^{\dagger 2,3}$, Virgina Wabano $^{4}$ and Jennifer Robertson-Wilson ${ }^{5}$
}

\begin{abstract}
Address: ${ }^{1}$ Primary Healthcare Research Unit, Memorial University of Newfoundland, St. John's, Newfoundland, Canada, ${ }^{2}$ School of Kinesiology and Health Studies, Queen's University, Kingston, Ontario, Canada, ${ }^{3}$ Kahnawake Schools Diabetes Prevention Project, Kahnawake, Quebec, Canada, ${ }^{4}$ A northern-rural Aboriginal Community, Ontario, Canada and ${ }^{5}$ Department of Kinesiology and Physical Education, Wilfrid Laurier University, Kington, Ontario, Canada

Email: Allison M Kirby* - amkirby@mun.ca; Lucie Lévesque - levesqul@post.queensu.ca; Virgina Wabano - geeaboonsh@hotmail.com; Jennifer Robertson-Wilson - jrobertsonwilson@wlu.ca

* Corresponding author †Equal contributors
\end{abstract}

\begin{abstract}
Background: Type 2 diabetes disproportionately affects Aboriginal peoples in Canada. Ample evidence shows that regular physical activity (PA) plays an important role in the prevention and treatment of type 2 diabetes. Evidence is beginning to emerge linking PA to the physical environment but little is known about the relationship between remote rural environments and PA involvement in Aboriginal peoples. This study's purpose was to investigate the relationship between perceptions of the environment and PA and walking patterns in Aboriginal adults in order to inform the planning and implementation of community-relevant PA interventions.
\end{abstract}

Methods: Two hundred and sixty three residents ( 133 women, mean age $=35.6$ years, $S D=12.3$ and I 30 men, mean age $=37.2$ years, SD = I3.I) from Moose Factory, Ontario were asked about environmental factors related to walking and PA involvement. Survey items were drawn from standardized, validated questionnaires. Descriptive statistics (means, standard deviations, percentages) were calculated. A series of hierarchical multiple regressions were performed to determine associations between walking and overall PA with perceived environmental variables.

Results: Hierarchical multiple regression to predict walking revealed significant associations between walking and perceived safety and aesthetics. Owning home exercise equipment predicted strenuous PA. Different aspects of the physical environment appear to influence different types of physical activities. The significant amount of variance in behaviour accounted for by perceived environmental variables (5.3\% walking) included safety, aesthetics, convenience, owning home exercise equipment and comfortable shoes for walking.

Conclusion: Results suggest that a supportive physical environment is important for PA involvement and that walking and activities of different intensity appear to be mediated by different perceived environmental variables. Implications for PA promotion in rural environments where Aboriginal people face many unique environmental features (e.g., bears, mosquitoes, extreme cold) are discussed. 


\section{Background}

The well-established connection between diabetes prevention and physical activity involvement [1-3] provides great impetus for promoting regular, physical activity involvement to sedentary or irregularly active persons at risk for diabetes. Initiatives to promote physical activity involvement increasingly encourage persons to become involved in moderate-intensity activities such as briskwalking to achieve health benefits $[4,5]$. Walking is reported to be the most popular type of physical activity in the general population and also in major subgroups such as overweight persons, seniors, persons living on low incomes and persons with limited education [6-8]. Walking is noted for its acceptability, accessibility, low cost, low intensity, and its ease of performance particularly when compared with many other physical activities [9]. For this reason, participating in walking may alleviate many of the barriers individuals report when attempting to participate in other physical activities [10]. This study examines both walking and general physical activity given that walking may not always be perceived as exercise or physical activity [11] and physical activity may not always include walking.

The ability to alter one's activity level in general and walking in particular is dependent upon a multitude of correlates that mediate or directly influence physical activity involvement [12-16]. Identifying relevant correlates is essential for the development of effective interventions to increase population levels of walking and physical activity involvement $[17,18]$. Recent attention to potential environmental influences upon walking and physical activity involvement underlies the purpose of the current study to explore associations between walking and physical activity and perceptions of the environment. In particular, the recent push to identify correlates as they apply to persons who are at increased risk for physical inactivity (e.g., Aboriginal persons [19-22]) also provides the backdrop to our study. These groups, who are often understudied or absent altogether from the literature $[19,23-25]$, are likely to report group-specific influences (e.g., cultural values and traditions) that may influence their physical activity involvement [24]. Understanding these influences is critical to inform study designs and interventions to enhance physical activity involvement.

The bulk of the research on physical activity correlates has focused on demographic (e.g., age, gender) and psychological (e.g., behavioural control, self-efficacy) variables $[16,22]$. Increasingly, researchers are recognizing the importance of environmental factors that may be associated with physical activity involvement $[16,26]$. For example, aesthetics and convenience of access to destinations have been found to be associated with walking in numerous studies [14]. At the same time, safety has been shown to be associated with walking in women but not in men [14]. At present it is unclear what environmental variables are differently associated with physical activity and walking [14], nor how these associations vary across diverse populations $[15,19]$. Moreover, we do not know how specific environmental features inherent to rural environments can influence physical activity involvement because the rural environment is largely ignored in the literature [21].

Although research into the link between the environment and physical activity is in its early stage and there is no conclusive evidence that improvements to the environment will enhance physical activity, it is clear that people who have access to safe places in which to walk, play, and be active are more likely to be active $[27,28]$. Given early evidence showing strong associations between environmental correlates and physical activity involvement and/ or walking $[16,18,29]$, and the lack of insight into environmental correlates specific to rural-living Aboriginal people, the purpose of this study was to investigate the relationship between Aboriginal community dwelling adults' perceptions of the environment and their physical activity and walking patterns. For the purposes of this study, environmental perception variables are defined as features of the environment that an individual views as affecting their ability to be physically active.

\section{Methods}

\section{Study context}

Moose Factory is an island community of approximately 2,500 people located near the mouth of the James Bay in Canada. Traditionally, this was a summer meeting place as the Cree people would travel to and from harvesting areas, living off the land year round. The Hudson's Bay Company established a fur trading post there in 1673, exposing the Cree population to the European way of life and forever altering their hunter-gatherer lifestyle [30]. During this time, a majority of the population began the transition from a nomadic way of life to that of permanent community settlers who relied heavily on external sources. It became common for the Cree to spend greater periods of time settled at or near the trading post where they would trade traditional tools and animal hides for European tools and food $[31,32]$. The signing of Treaty No. 9 in 1905 solidified the relationship between the Cree people of Northern Ontario and the Federal Department of Indian Affairs. In 1907 a 'Native reserve' was established and a residential school was operated on the island [32]. Not only were the language and cultural traditions of the Cree affected, but the dietary habits and activity patterns were also influenced greatly during this period of acculturation and westernisation. Lark Ritchie [32], a local anthropologist describes the transition that began with the introduction of a European way of life: 
We became dependent. Slowly; not violently; not abruptly; we continued to hunt and we trapped; but instead of being travellers, some of us came back to the same place. Rather than families travelling together, they stayed near the posts, and the men went out to hunt and trap, and came back. Our trading had become a commercial venture, and as experienced hunters and trappers, we actually profited by our skills. We had come to know 'capitalism' and 'material possession'. Permanent pots and pans, metal spoons and forks, dishes, extra clothing, a permanent roof. Too much to carry in a canoe. Too much to leave if we travelled. We had become dependent on a relationship designed to take us out of our Native land...

The traditional lifestyle of earning a living and surviving off the land has thus largely passed. More common now are daily hunting trips or trips lasting a few weeks at time. Qualitative and descriptive observation suggest a high calorie diet and sedentary activity patterns characterize the current lifestyle behaviours of many Moose Factory community members [30].

This significant shift in lifestyle brought with it a new era of health challenges for the James Bay Cree and for Aboriginal communities across Canada. In 1998, the direct age-standardized prevalence of diabetes in Moose Factory was $10.3 \%$, more than double the estimated rate of diabetes in the Canadian population $(\approx 5 \%)$ [33]. Additionally, the 2002/03 First Nations Regional Longitudinal Health Survey, which gathers information about the health, wellness, and health determinants of First Nations living in First Nations communities across Canada, estimated the rate of diabetes in First Nations communities to be at $14.5 \%$ [34].

Trends in activity and diet are also of concern. Although the 2001 Aboriginal People's Survey suggests that 56\% of First Nations people in Canada participate in sports, games, or recreational activities [35], other reports suggest that $47 \%$ of Aboriginal people in Canada are moderately physically active [36] and that in 2003, only $21.3 \%$ of the First Nations population in Canada participated in 'sufficient physical activity' $(30+$ minutes of activity with increased heart rate and breathing 4+ days a week). This report also revealed that $32.5 \%$ of First Nations persons consume soft drinks on a daily basis and 7.9\% consume fast food on a daily basis [34].

Moose Factory community members who have become increasingly concerned with the high prevalence of Type 2 diabetes in their community have recently sought out the expertise of an established diabetes prevention team to aid in the development of a diabetes prevention program for their community. The Kahnawake Schools Diabetes Prevention Project Centre for Research and Training in Diabetes Prevention, the research and training arm of the
Kahnawake Schools Diabetes Prevention Project (KSDPP $[37,38])$, is collaborating with the community to address diabetes through initiatives such as this one.

\section{Recruitment}

Two-hundred and seventy-four community members were recruited through a booth set up inside the only shopping complex on the island, posters displayed strategically throughout the community, and advertisements placed on the local television channel and on the two local radio stations. Study eligibility criteria included the following: be 18 years of age or older, have lived in the community for five years or more, and be physically able to participate in walking or regular physical activity. Although we did not specifically ask about ethnicity, we are confident that our sampling strategy yielded a majority of people from Cree descent because most of the transient population (i.e., living in the community for less than five years) would have been excluded from our sample. Eleven people were excluded based on their selfreported inability to partake in physical activity.

\section{Participants}

One hundred and thirty women (mean age $=35.6$ years, $\mathrm{SD}=12.3$ ) and 133 men (mean age $=36.3$ years, $\mathrm{SD}=$ 12.7) volunteered to participate in this study. Given that Statistics Canada did not completely enumerate Moose Factory during the 1996 and 2001 Censuses [39], it is not possible to confirm the representativeness of our sample. However, based on numbers compiled by several different community groups (e.g. Moose Cree Band Council, the Weeneebayko General Hospital) we estimate that this sample of 263 adults represents just over $10 \%$ of the entire Moose Factory population. Community members were informed that their participation was completely voluntary and anonymity was assured. Verbal informed consent was obtained prior to participation in accordance with the KSDPP Code of Research Ethics [40] and the relevant university research ethics board. Community members who completed the questionnaire were entered into a cash draw for $\$ 100.00$.

\section{Measures and Procedures}

A brief 15-item survey was developed to assess environmental perceptions, walking, and physical activity. Survey items were drawn from standardized, validated questionnaires $[29,41]$ and refined with community input. For example, in response to community members' request that the survey be brief (in order to reduce participant burden) we selected a reduced number of items, deemed by the group to be most relevant for Moose Factory. Respondents completed the survey in approximately six minutes at a table set up in a quiet area in the shopping complex. This location was chosen following advice from community members who considered our initial data col- 
lection protocol, a door-to-door survey, as being too invasive and presumptuous.

\section{Demographics and body mass index}

Participants' self-reported age, gender, height and weight were recorded. Height and weight were used to calculate body mass index (BMI) [weight $(\mathrm{kg}) /$ height $\left.\left(\mathrm{m}^{2}\right)\right]$.

\section{Physical activity}

Items from the Godin Leisure-Time Exercise Questionnaire [41] were used to assess physical activity involvement. Questions required participants to separately recall frequency and duration of vigorous, moderate, and light physical activity involvement over the past 7-day period. Two week test-retest reliability coefficients for vigorous, moderate, light intensities have been reported to be: 0.94 , $0.46,0.48$ respectively [41]. Two outcome variables were constructed from this assessment: 1 ) total weekly physical activity involvement (i.e., total number of minutes spent in strenuous, moderate, and light over the previous 7 days), and 2) meeting physical activity recommendations outlined in Canada's Physical Activity Guide to Health Living (i.e., $>30$ minutes of moderate and/or $>60$ minutes of light physical activity five or more days a week [42]).

\section{Walking}

Self-reported frequency (times per week) and duration of walking (in minutes, at any intensity) in the past 7 days were multiplied to yield two outcome variables: 1) total weekly walking (i.e., total number of minutes spend walking over the previous 7 days), and 2) meeting physical activity recommendations (i.e., engaging in a minimum of 60 minutes of walking at least five days a week [42]).

\section{Environmental perceptions}

Environmental attribute items were selected from a review of studies investigating environmental factors that have been found to be associated with adults' involvement in physical activity $[18,29]$. Three separate items were used to assess community features: (a) 'convenience': convenience of shops stores and other places to buy things near by, (b) 'safety': safety of the community for walking, and (c) 'aesthetics': interesting features to look at while walking in the community. Each item was measured on a fourpoint scale $(1=$ strongly agree to $4=$ strongly disagree $)$. Two items were used to assess home-level environmental supports: (a) owning home exercise equipment, and (b) having sneakers/shoes comfortable enough for walking short distances. Reported absence/presence of these items were recorded.

\section{Analyses}

Descriptive statistics (means, standard deviations, frequencies, percentages) were calculated. Bivariate relationships between demographic variables (i.e., age, gender, and BMI) and meeting walking and physical activity recommendations were examined by conducting chi-square analysis $(p<.05)$. Hierarchical multiple regressions were conducted to determine whether demographic and environmental variables were associated with total weekly walking and total weekly physical activity involvement. In each regression, gender was entered in the first step, followed by age and then BMI in the second and third steps, respectively. In the final step, community aesthetics, convenience, and safety, home exercise equipment, and walking/running shoe ownership were entered together.

Given that degree of intensity is lost in the all-intensity measure of total weekly physical activity involvement, we also conducted intensity-specific analyses for each of the following: light weekly minutes, moderate weekly minutes, and strenuous weekly minutes of physical activity. Our rationale for this subset of analyses is founded on evidence suggesting that physical activities of varying intensity may have different predictors and moderators [28]. To examine the effects of perceived environmental variables on physical activity for each different intensity, only those persons reporting involvement in a given intensity were included in the analysis. In other words, those persons reporting zero minutes of strenuous physical activity were excluded from the analysis examining weekly minutes of strenuous physical activity, as we were explicitly interested in the variables affecting those actually partaking in the activity intensity being investigated.

\section{Results}

Eighty (30.4\%) of the 263 respondents reported meeting current Canadian physical activity recommendations (i.e., $\geq 30$ minutes of moderate physical activity at least five days per week or $\geq 60$ minutes of light physical activity at least five days per week) [42]. Similarly, 79 respondents (30\%) reported walking enough to meet physical activity recommendations $(\geq 30$ minutes of walking at least five days per week) while 212 respondents $(80.6 \%)$ reported walking on at least one occasion throughout the week. Over one third of study participants (i.e., 34.5\%) were considered class I obese (i.e., BMI over 30 and less than 35 ) and an additional $21 \%$ were considered class II obese or above (i.e., BMI greater than 35; [43]). Total weekly physical activity involvement decreased with increasing BMI $\chi^{2}(4, \mathrm{~N}=253)=11.72, p=.02$, and total weekly walking decreased with increasing age $\chi^{2}(2, \mathrm{~N}=263)=$ $7.18, p=.03$, and increasing BMI $\chi^{2}(4, \mathrm{~N}=253)=19.59$, $p=.001$. Men were more likely than women to report sufficient levels of physical activity involvement $\chi^{2}(1, \mathrm{~N}=$ $263)=5.14, p=.016$, but no more likely to report sufficient levels of walking $(p>.05)$. See Table 1 . 
Table I: Participant Characteristics

\begin{tabular}{llll}
\hline Variable & $\mathrm{N}$ & Active (\%) $^{\mathrm{a}}$ & Sufficient Walking (\%) \\
\hline GENDER & & & \\
Women & 133 & 24.06 & 31.58 \\
Men & 130 & 36.92 & 28.46 \\
& & & \\
AGE & & & \\
I8-34 & 130 & 36.15 & 37.69 \\
$35-54$ & 110 & 26.36 & 22.73 \\
$\geq 55$ & 23 & 17.39 & 21.74 \\
& & & \\
BMI & & & \\
I8.5-24.9 & 29 & 48.28 & 62.07 \\
$25-29.9$ & 83 & 37.35 & 33.73 \\
$30-34.9$ & 87 & 24.14 & 24.14 \\
$35+$ & 53 & 18.87 & 18.87 \\
\end{tabular}

a Active $=\geq 30$ minutes of moderate physical activity at least five days per week or $\geq 60$ minutes of light physical activity at least five days per week

b Sufficient walking $=\geq 30$ minutes of walking at least five days per week

\section{Walking}

Total weekly walking variable scores were transformed using square root transformation to normalize the positively skewed data. Predictor variables safety and aesthetics were also transformed using square root transformations [44]. Hierarchical multiple regression analysis with the dependent variable square root of total weekly walking revealed significant associations with age, $\mathrm{BMI}$, and perceived environmental variables in the final model (see Table 2). Gender was entered in the first step, but did not contribute significantly to the variance $(p>$ $.05)$. In the second step, age was entered and it accounted for $3.3 \%$ of the variance $F(1,253)=8.59(p<.05)$. BMI, entered in the third step, explained an additional $5.9 \%$ of the variance in total weekly walking $\mathrm{F}(1,252)=16.44(p$ $<.001)$. In the final step, perceived environmental variables accounted for an additional $5.3 \%$ of the variance $\mathrm{F}$ $(5,247)=3.04(p<.05)$. Both square root of safety and aesthetics were significantly related to total weekly walking when all other variables were controlled for $(\mathrm{p}<.05$; Beta 0.130, 0.186 respectively).

\section{All intensity physical activity}

A second hierarchical multiple regression analysis with the dependent variable square root of all intensity physical activity (weekly total; transformed due to being positively skewed [44]) revealed significant associations with gender, age, and BMI (see Table 2). Gender was entered in the first step and accounted for $3.4 \%$ of the variance $\mathrm{F}$ $(1,251)=8.74(p<.05)$. Age was entered in the second step and explained $3.9 \%$ of the variance $F(1,250)=10.55$ $(p<.001)$. BMI, entered in the third step, accounted for $2.9 \%$ of the variance F $(1,249)=8.14(p<.05)$. Perceived environmental variables were entered in the final step, but did not contribute significantly to the variance $(p>.05)$.

\section{Strenuous, moderate and light physical activity}

The log of weekly strenuous minutes of physical activity was entered into a hierarchical multiple regression as the dependent variable $(n=120)$. No demographic or perceived environmental variables contributed significantly to the variance $(p>.05)$. The log of weekly moderate minutes of physical activity was entered into a hierarchical multiple regression as the dependent variable $(n=165)$. No demographic or perceived environmental variables significantly contributed to the variance in moderate physical activity $(p>.05)$. Using the log of weekly minutes of light physical activity as the dependent variable ( $\mathrm{n}=$ 242) revealed significant associations with BMI. Gender and age, respectively entered in steps one and two did not significantly contribute to the variance $(p>.05)$. BMI, entered in the third step, accounted for $1.7 \%$ of the variance $F(1,232)=4.11(p<.05)$. Perceived environmental variables, entered in the last step, were not significantly related to involvement in light physical activity ( $p>.05)$.

\section{Discussion}

The purpose of this study was to investigate the relationship between Aboriginal community dwelling adults' perceptions of the environment and their physical activity and walking patterns. Our examination of participant demographics showed that, consistent with results from the 2002/03 First Nations Regional Longitudinal Health Survey [34], just over half of respondents could be classified as obese [43]. Taking into account that self-reported height and weight are prone to bias, in that persons tend to overestimate their height and underestimate their weight [45], we can assume that these results actually underestimate the prevalence of obesity in our sample. This extreme level of overweight and obesity in our sample merits consideration in light of cross-sectional studies which have consistently shown a graded, negative relationship between physical activity involvement and BMI [16]. The high levels of overweight and obesity observed may be contributing to the low levels of physical activity in this population and must be considered when interventions are designed and implemented.

Consistent with previous findings on walking $[46,47]$, community walking had strong relationships with perceived environmental variables. Specifically, aesthetics and safety were significantly related to walking when all other variables were controlled for. Thus, different aspects of the physical environment appear to influence different types of physical activities, consistent with the notion that environmental factors have their strongest effect on behaviours that occur in those same environments [47]. It 
Table 2: Results of hierarchical multiple regression to explain walking and physical activity by perceived environmental variables

\begin{tabular}{|c|c|c|c|}
\hline Step & Variable in model & Adjusted $R^{2}$ change & Standardized Beta \\
\hline \multicolumn{4}{|c|}{ Associations with total minutes of walking per week $(n=262$ ) } \\
\hline I. & Gender & .001 & .084 \\
\hline 2. & Age & .037 & $-.140 *$ \\
\hline 3. & BMI & .079 & $-.256 * *$ \\
\hline \multirow[t]{5}{*}{4.} & Home equipment & & -.004 \\
\hline & Having shoes & & .090 \\
\hline & Sqrt Aesthetics & .052 & $.186^{*}$ \\
\hline & Convenience & & .048 \\
\hline & Sqrt Safety & & $-.130 *$ \\
\hline \multicolumn{4}{|c|}{ Associations with total minutes of all intensity physical activity $(n=262)$} \\
\hline I. & Gender & .034 & $-.163 *$ \\
\hline 2. & Age & .039 & $-.180 * *$ \\
\hline 3. & BMI & .029 & $-.164 *$ \\
\hline \multirow[t]{5}{*}{4.} & Home equipment & & -.047 \\
\hline & Having shoes & & .019 \\
\hline & Sqrt Aesthetics & .017 & .187 \\
\hline & Convenience & & -.021 \\
\hline & Sqrt Safety & & -.094 \\
\hline \multicolumn{4}{|c|}{ Associations with total minutes of strenuous physical activity per week $(n=120)$} \\
\hline I. & Gender & .015 & $-.15 \mid$ \\
\hline 2. & Age & .024 & -.187 \\
\hline 3. & BMI & .029 & -.163 \\
\hline \multirow[t]{5}{*}{4.} & Home equipment & & -.224 \\
\hline & Having shoes & & .029 \\
\hline & Sqrt Aesthetics & & .124 \\
\hline & Convenience & & .032 \\
\hline & Sqrt Safety & .072 & -.030 \\
\hline \multicolumn{4}{|c|}{ Associations with total minutes of moderate physical activity per week $(n=165)$} \\
\hline I. & Gender & .014 & -.090 \\
\hline 2. & Age & .022 & -.127 \\
\hline 3. & BMI & .004 & -.084 \\
\hline \multirow[t]{5}{*}{4.} & Home equipment & & .114 \\
\hline & Having shoes & & .049 \\
\hline & Sqrt Aesthetics & .028 & .027 \\
\hline & Convenience & & .001 \\
\hline & Sqrt Safety & & -.125 \\
\hline \multicolumn{4}{|c|}{ Associations with total minutes of light physical activity per week $(n=242)$} \\
\hline I. & Gender & .001 & .007 \\
\hline 2. & Age & .013 & -.090 \\
\hline 3. & BMI & .017 & $-.147^{*}$ \\
\hline \multirow[t]{5}{*}{4.} & Home equipment & & .042 \\
\hline & Having shoes & & .017 \\
\hline & Sqrt Aesthetics & .007 & -.031 \\
\hline & Convenience & & -.002 \\
\hline & Sqrt Safety & & -.060 \\
\hline
\end{tabular}

$*_{p}<.05, * * p<.001$; Sqrt= square root transformation

makes sense that feeling unsafe (e.g., from wild animals) would have a stronger influence on walking on a community trail than on participating in a yoga class at the local community centre.

The significant amount of variance in behaviour accounted for by perceived environmental variables highlights the importance of considering environmental factors in intervention and determinant studies aimed at increasing the understanding of physical activity involvement. Additionally, this large amount of variance is particularly substantial if it is actually "added" explained variance. In other words, if these perceived environmental features are contributing to the prediction of behaviour above and beyond demographic, psychological, social, and cultural determinants already demonstrated to affect physical activity involvement, [12] this contribution is indeed noteworthy. Furthermore, it is important to con- 
sider the implications of these effects once they are multiplied over the entire population [28], where the influence on a population's physical activity level could be substantial [14]. Future work needs to examine integrated intervention models that include intrapersonal, interpersonal, and environmental correlates specific to Aboriginal adults living in rural communities to determine the relative contribution of each ecological dimension to people's involvement in walking and physical activity.

Our findings add to and are consistent with previous research showing that environmental aesthetics are related to increased walking in the community $[25,46-$ 50]. Given that many rural communities such as Moose Factory are characterized by pleasing natural environmental features (e.g., waterfront vistas), this may represent a promising avenue for encouraging physical activity in specific community locations and/or for improving the aesthetic appeal of other community locations.

Sharpe and colleagues also found that persons perceiving greater safety were more likely to meet physical activity recommendations [48]. Unlike the present study, however, the authors did not differentiate between walking and total physical activity. More research is needed to investigate the association between different types of physical activity, including walking, with perceived safety before conclusions can be drawn. While safety does appear to be a correlate of physical activity across a wide range of environments (e.g. rural and urban) [51], we can speculate that its importance in a northern-rural environment is distinctive from that of most urban environments. For example, while it is highly unlikely that an individual in an urban centre refrains from physical activity to avoid environmental threats such as bears, this threat is real for people living in communities such as Moose Factory. It therefore follows that environment-specific strategies will need to be developed to address safety issues inherent to a given environment. It is clear that additional qualitative research is required to further investigate specific safety issues (e.g. from violent crime, bears, dogs, etc) relevant to physical activity in different types of Aboriginal communities.

That perceptions of the surrounding environment are more influential to walking than to general levels of physical activity is fairly consistent with the literature and supports the notion that environmental factors will have their strongest effects on behaviours that occur in those same environments $[16,23,51]$. This confirms that the unique environment of a remote rural community needs to be accounted for in intervention plans to promote walking. Intervention strategies might include ways to counter unsafe situations (e.g., walking with a group rather than alone) or ways in which to enhance safety (e.g., fencing an outdoor area where walking can take place).

To better understand the factors that influence community members' physical activity and walking, a wider range of correlates must be investigated (e.g. traditional beliefs). An increased understanding of how these correlates interact to influence behaviour in this understudied segment of the population is needed. Research conducted by Lavallée suggests that including Aboriginal core values, beliefs and healing practices in physical activity programming will increase Aboriginal people's adherence and connection to such programs [52]. Including cultural values such as smudging, tobacco bundles, and purification ceremonies in physical activity programs will encourage a more wholistic (this spelling is used to reflect the Aboriginal philosophy of the "whole" in which "everything is related by virtue of shared origins and in which, by extension, the human being is considered an entire whole, that is, mentally, physically, spiritually, and emotionally..." [53]) view of physical activity and allow healing at multiple levels (e.g. physical, mental, emotional, and spiritual) [52].

Our results suggest that one's environment is an important factor to consider when physical activity participation is in question. Environment factors should not be ignored, but rather be considered in addition to and not instead of other social and individual level variables. Simply creating supportive environments for physical activity may not be sufficient and intervention studies need to consider individual, social environmental and environmental variables [54].

Some limitations to the current study deserve mention. The cross-sectional design of the investigation limits the conclusions that can be drawn and the use of convenience sampling limits the generalizability of results. Objective measures of the environment were not collected, as the study was designed to investigate community members' perceptions of their environment. Subsequent studies should investigate the relationship between perceived and objective measures of the environment. Reliance on selfreport to assess physical activity and walking may have yielded inflated estimates of these behaviours. Similarly, self-reported height and weight may have led to an underestimation of levels of overweight and obesity. Despite these limitations, our findings provide new information concerning an environment and population segment that has been largely understudied. Additionally, the results provide supportive evidence in an area where there is growing interest, but limited published data [45]. The information gathered in this study can be utilized by community members to design more appropriate and effective physical activity interventions. 
Results indicate that the relationship between physical activity and the environment is complex whereby different environmental variables appear to be associated with different types of physical activities. Further investigation is needed into methods for altering persons' perception of their community environment. Possibly improving community members' perceptions concerning safety and aesthetics could foster increased physical activity involvement [55].

\section{Recommendations for community intervention}

A compilation of the information generated by this investigation provides valuable direction for the newly formed diabetes prevention team in this community and anyone else planning interventions in this community or in other rural Aboriginal communities in Canada. Our results suggesting that perceived environmental aesthetics and safety are both related to walking behaviour in the community might serve as a starting point for intervention design. A summary of the information garnered was reported back to the community through a community newsletter, a presentation to the local health committee and diabetes prevention team and through posters displayed throughout the community. In addition, community member's input and approval was solicited throughout the writing process.

\section{Conclusion}

These findings indicate that walking appears to be influenced differently by the surrounding environment than by general physical activity involvement. As well, similar determinants appear to affect individuals living in very different environments, but the underlying reasons may be quite varied and further investigation is warranted. Study results provide much needed information concerning the determinants that mediate physical activity participation in a rural environment with an understudied population segment. Several significant associations were documented, demonstrating the importance of considering environmental factors in physical activity intervention and correlate studies.

Because current findings suggest a possible variation in correlates across age, gender, and BMI, specific consideration for each of these attributes is recommended in subsequent investigations. Furthermore, the findings underscore the necessity of additional research to further the understanding of how perceived convenience; aesthetics, safety, exercise equipment in the home, presence or absence of comfortable shoes, and other environmental factors may influence physical activity levels in different population strata across varied environments. Future investigations should include a wide range of possible correlates in prospective and intervention designs that are behaviour-specific. Attributes specific to a particular phys- ical activity type (e.g. intensity level) in a particular context and setting also need to be considered.

\section{Competing interests}

The author(s) declare that they have no competing interests.

\section{Authors' contributions}

AK participated in the conception and design of the study, the acquisition of data, analysis and interpretation of data, and the drafting of the manuscript. LL was involved in the conception and design of the study, analysis and interpretation of data, and the drafting of the manuscript. VW participated in the design of the study and the acquisition of data. JRW was involved in the analysis and interpretation of data, performed the statistical analysis, and critically revised the manuscript. All authors read and approved the final manuscript.

\section{Acknowledgements}

We are grateful to the host community of Moose Factory for their participation and cooperation. This research was supported by the Canadian Institutes for Health Research (CIHR), the Kahnawake Schools Diabetes Prevention Project, and by the Kahnawake Community Advisory Board. We thank Katherine Turner, Christina Delaney, Allen Sailors, Fred Rickard, Bill Pearce, Elaine Power, Alex McComber, Jon Salsberg, Dr. Ann

McCaulay, Beth Doxsee, and the KSDPP Research Team. AK is supported by a KSDPP Master's Scholarship (through CIHR funding).

\section{References}

I. Knowler WC, Barrett-Connor E, Fowler SE, Hamman RF, Lachin JM, Walker EA, Nathan DM: Reduction in the incidence of type 2 diabetes with lifestyle intervention or metformin. $N$ Engl J Med 2002, 346:393-403.

2. Kriska A: Physical activity and the prevention of type $\mathbf{2}$ diabetes mellitus: how much for how long? Sports Med 2000, 29:|47-|5|.

3. Williamson DF, Vinicor F, Bowman BA, Centers For Disease Control And Prevention Primary Prevention Working Group: Primary prevention of type 2 diabetes mellitus by lifestyle intervention: implications for health policy. Ann Intern Med 2004, 140:95I-957.

4. Pate RR, Pratt M, Blair SN, Haskell WL, Macera CA, Bouchard C Buchner D, Ettinger W, Heath GW, King AC, Kriska A, Leon AS, Marcus BH, Morris J, Paffenbarger RS, Patrick K, Pollock ML, Rippe JM, Sallis JF, Wilmore JH: Physical activity and public health. A recommendation from the Centers for Disease Control and Prevention and the American College of Sports Medicine. JAMA 1995, 273:402-407.

5. Whitt MC, DuBose KD, Ainsworth BE, Tudor-Locke C: Walking patterns in a sample of African American, Native American, and Caucasian women: the cross-cultural activity participation study. Health Educ Behav 2004, 3 I (4 Suppl):45S-56S.

6. Eyler AA, Brownson RC, Bacak SJ, Housemann RA: The epidemiology of walking for physical activity in the United States. Med Sci Sports Exerc 2003, 35: I529-1536.

7. Brownson RC, Jones DA, Pratt M, Blanton C, Health GW: Measuring physical activity with the Behavioral Risk Factor Surveillance System. Med Sci Sports Exerc 2000, 32:1913-1918.

8. Craig CL, Russell SJ, Cameron C, Beaulieu A: Foundations for joint action: reducing physical inactivity Ottawa: Canadian Fitness and Lifestyle Research Institute; 1999.

9. Siegel P, Brackbill R, Health GW: The epidemiology of walking for exercise: implications for promoting activity among sedentary groups. Am J Public Health 1995, 85:706-710. 
10. Rhodes RE, Brown SG, Mclntyre CA: Integrating the perceived neighbourhood environment and the theory of planned behaviour when predicting walking in a Canadian adult sample. Am J Health Promot 2006, 2 I : I I - I I8.

II. Henderson KA, Ainsworth BE: Enablers and constraints to walking for older African-American and American Indian women: the Cultural Activity Participation Study. Res Q Exerc Sport 2000, 71:313-321.

12. Dishman RK, Buckworth J: Increasing physical activity: a quantitative synthesis. Med Sci Sports Exerc 1996, 28:706-7I9.

13. Buckworth J: Exercise determinants and interventions. Int Sport Psychol 2000, 31:305-320.

14. Owen N, Humpel N, Leslie E, Bauman A, Sallis JF: Understanding environmental influences on walking: review and research agenda. Am J Prev Med 2004, 27:67-76.

15. Owen N, Leslie J, Salmon J, Fotheringham MJ: Environmental determinants of physical activity and sedentary behavior. Exerc Sport Sci Rev 2000, 28:153-158.

16. Trost SG, Owen N, Bauman A, Sallis JF, Brown W: Correlates of adults' participation in physical activity: review and update. Med Sci Sports Exerc 2002, 34:1996-2001.

17. Jones WK: Understanding barriers to physical activity is a first step in removing them. Am J Prev Med 2003, 25:2-4.

18. Humpel N, Owen N, Leslie E: Environmental factors associated with adult's Participation in physical activity: A review. Am J Prev Med 2002, 22:188-199.

19. Coble JD, Rhodes RE: Physical activity and Native Americans: a review. Am J Prev Med 2006, 31:36-46.

20. Thompson JL, Wolfe VK, Wilson N, Paradilla MN, Perez G: Personal, social, and environmental correlates of physical activity in Native American women. Am J Prev Med 2003, 25:53-60.

21. Plotnikoff RC, Mayhew A, Birkett N, Loucaides CA, Fodor G: Age, gender and urban-rural differences in the correlates of physical activity. Prev Med 2004, 39: I I I 5- I I 25.

22. Nies MA, Kershaw TC: Psychosocial and environmental influences on physical activity and health outcomes in sedentary women. J Nurs Scholarsh 2002, 34:243-249.

23. Sallis JF, Owen N: Physical activity and behavioral medicine Thousand Oaks, California: Sage Publications; 1999.

24. Taylor WC, Baranowski T, Rohm Young D: Physical activity interventions in low-income, ethnic minority, and populations with disability. Am J Prev Med 1998, 15:334-343.

25. King AC, Castro C, Wilcox S, Eyler AA, Sallis JF, Brownson RC: Personal and environmental factors associated with physica inactivity among different racial-ethnic groups of U.S. middle-aged and older-aged women. Health Psychol 2000, 19:354-364.

26. Sallis JF, Cervero RB, Ascher W, Henderson KA, Kraft MK, Kerr J: An ecological approach to creating active living communities. Annu Rev Public Health 2006, 27:297-322.

27. Handy SL, Boarnet MG, Ewing R, Killingsworth RE: How the built environment affects physical activity: views from urban planning. Am J Prev Med 2002, 23:64-73.

28. Sallis JF, Glanz K: The role of built environments in physical activity, eating, and obesity in childhood. Future Child 2006 16:89-108.

29. Sallis JF, Johnson MF, Calfas KJ, Caparosa S, Nichols JF: Assessing perceived physical environmental variables that may influence physical activity. Res Q Exerc Sport 1997, 68:345-35I.

30. Abonyi S: Sickness and symptom: Perspectives on diabetes among the Mushkegowuk Cree. In Unpublished PhD thesis McMaster University, Anthropology; 200I.

31. Honigmann Jj: Kaska. In Handbook of North American Indians Volume 6. Edited by: Helm J. Washington, DC: Smithsonian Institution; 1981:442-450

32. Ritchie L: Our roots-Chapleau Cree history-the people of Moosonee-Moose Factory Area. [http://www.geocities.com/ chapleaucree/mfhist.html].

33. Maberley DL, King W, Cruess AF: The Prevalence of Diabetes in the Cree of Western James Bay. Chronic Dis Can 200I, 21:3.

34. Gray J, Clarke S, Tournier C, Schnarch B, Paul M: The First Nations regional longitudinal health survey on children, youth and adults (RHS) 2002-03. Third Session of the Permanent Forum on Indigenous Issues: 19 May 2004; New York.

35. Statistics Canada: 200I Aboriginal Peoples Survey. In Aboriginal Peoples Survey 2001 initial findings Ottawa, Statistics Canada.
36. Bryan SN, Tremblay MS, Pérez CE, Ardern Cl, Katzmarzyk PT: Physical activity and ethnicity: Evidence from the Canadian Community Health Survey. Can J Public Health 2006, 97:27I-276.

37. Macaulay AC, Paradis G, Potvin L, Cross EJ, Saad-Haddad C McComber A, Desrosiers S, Kirby R, Montour LT, Lamping DL, Leduc N, Rivard M: The Kahnawake Schools Diabetes Prevention Project: intervention, evaluation, and baseline results of a diabetes primary prevention program with a native community in Canada. Prev Med 1997, 26:779-90.

38. Macaulay AC, Cargo M, Bisset S, Delormier T, Lévesque L, Potvin L: Kanien'kehá:ka (Mohawk) ways for the Primary Prevention of Type 2 diabetes: the Kahnawake Schools Diabetes Prevention Project. In Indigenous Peoples and Diabetes: Community Empowerment and Wellness Edited by: Ferreira ML, Lang GC. Durham NC: Carolina Academic Press; 2005:407-434.

39. Statistics Canada: 2001 Census Ottawa, Ontario; 2001

40. Macaulay AC, Delormier T, McComber AM, Cross E], Potvin L, Paradis G, Saad-Haddad C, Desrosiers S, Kirby R: Participatory research with Native community of Kahnawake creates innovative research ethics: The Kahnawake Schools Diabetes Prevention Project. Can J Public Health 1988, 89:105- 108.

4I. Godin G, Shephard RJ: A simple method to assess exercise behavior in the community. Can J Appl Sport Sci 1989, I0:|4I-I46.

42. Canada's Physical Activity Guide to Healthy Living [http:// www.phac-aspc.gc.ca/pau-uap/paguide/index.html]

43. Canadian guidelines for body weight classification in adults: Health Canada. 2003.

44. Rummel RJ: Applied factor analysis Evanston, IL: Northwestern University Press; 1970.

45. Spencer EA, Appleby PN, Davey GK, Key TJ: Validity of selfreported height and weight in 4808 EPIC-Oxford participants. Public Health Nutr 2002, 5:56I-565

46. Grundy SM, Blackburn G, Higgins M, Lauer R, Perri MG, Ryan D Physical activity in the prevention and treatment of obesity and its comorbidities: evidence report of independent panel to assess the role of physical activity in the treatment of obesity and its complications. Med Sci Sports Exerc 1999, 31:1493-1500.

47. Giles-Corti B, Donovan J: Socioeconomic status differences in recreational physical activity levels and real and perceived access to a supportive physical environment. Prev Med 2002, 35:60I-6II.

48. Sharpe PA, Granner ML, Hutto B, Ainsworth BE: Association of environmental factors to meeting physical activity recommendations in two South Carolina Counties. Am J Health Promot 2004, 18:25I-257.

49. Humpel N, Owen N, Leslie E, Marshall AL, Bauman A, Sallis JF: Associations of location and perceived environmental attributes with walking in neighborhoods. Am J Health Promot 2004, I8:239-242.

50. Giles-Corti B, Broomhall MH, Knuiman M, Collins C, Douglas $\mathrm{K}, \mathrm{Ng}$ $\mathrm{K}$, Lange $\mathrm{A}$, Donovan RJ: Increasing walking how important is distance to, attractiveness, and size of public open space? Am J Prev Med 2005, 28:169-176.

51. Ball K, Bauman A, Leslie E, Owen N: Perceived environmental aesthetics and convenience and company are associated with walking for exercise among Australian adults. Prev Med 200I, 33:434-440.

52. Lavallé LF: Physical activity and healing through the medicine wheel. Pimatisiwin 2007, 5:5-24. (Antone, Gamlin, \& Provost-Turchetti, 2003 as cited by Antone \& Imai, 2006, p. 7)

53. Antone G, Imai J: Defining Aboriginal health literacy in a Canadian context: bringing Aboriginal knowledge into practise. Proceedings of the Canadian Association for the study of Adult Education National Conference: 28-30 May 2006; Toronto 2006:7-12.

54. Carnegie MA, Bauman A, Marshall AL, Mohsin M, Westley-Wise V, Booth ML: Perceptions of the physical environment, stage of change for physical activity and walking among Australian adults. Res Q Exerc Sport 2002, 73:|46-I55.

55. Bandura A: Social foundations of thought and action Englewood Cliffs, NJ: Prentice-Hall; 1986. 